\title{
A Homeopatia Aplicada a Desordem Temporomandibular e Dor Orofacial
}

\section{The Applied Homeopathy the Temporomandibular Disorder and Orofacial Pain}

\author{
Rosy de Oliveira Nardy ${ }^{1}$
}

Artigo

Original

\begin{tabular}{|c|c|}
\hline Palavras-chaves: & Resumo \\
\hline $\begin{array}{l}\text { Desordem Tem- } \\
\text { poromandibular }\end{array}$ & $\begin{array}{l}\text { Este estudo trata de uma revisão de literatura sobre os fundamentos da } \\
\text { Homeopatia como possibilidade terapêutica baseada na valorização do } \\
\text { indivíduo como um ser único, individualiazado, de características físicas, }\end{array}$ \\
\hline Dor Orofacial & $\begin{array}{l}\text { emocionais e espirituais peculiares. As possibilidades farmacológicas } \\
\text { oferecidas pela Homeopatia abrangemas cacartcterísticas multidisciplinares }\end{array}$ \\
\hline Homeopatia & $\begin{array}{l}\text { necessárias para o tratamento do paciente portador de Desordem } \\
\text { Temporomandibular e Dor Orofacial no Programa de Extensão e Pesquisa } \\
\text { Núcleo da Dor - PROEXT / UniFOA. }\end{array}$ \\
\hline
\end{tabular}

\begin{abstract}
This study treats of a literature revision on the foundations of the Homeopathy as therapeutic possibility based on the individual's valorization as a unique being, individualized of physical characteristics, emotional and spiritual peculiars. The pharmacological possibilities offered by the Homeopathy comprise the multidisciplinary characteristics necessary for the treatment of the patient's bearer of Temporomandibular Disorder and Orofacial Pain in the Program of Extension and Nucleus Researches of the Pain-PROEXT / UniFOA.
\end{abstract}

Key words:

Temporomandibular Disorder

Orofacial Pain

Homeopathy

\section{Introdução}

Observando as leis universais, pressupõe-se que o encontro da Homeopatia com a DTM e DOF seria inevitável, uma vez conhecedores da lei da atração entre os semelhantes "Simillia Similibus Curentur".

As características multifatoriais desencadeantes de vários sintomas relatados pelos pacientes nem sempre se enquadram numa única classificação e, por diversas vezes, o paciente sofre de mais de uma desordem, como se a presença de uma desordem primária contribuísse para a perpetuação de outra. Okeson (2000).

A observação e busca incansável do entendimento desta nobre forma de vida: o ser humano, uma entidade única e livre em expressar-se enquanto criatura e criador do seu bem estar e de seu desequilíbrio patológico, levou o clínico da dor a ampliar sua visão, transpor obstáculos e unir em caráter cientificamente comprobatório as diversas especialidades médico-odontológicas.

No caminho desta fusão interdisciplinar, estava a Totalidade dos Sintomas, definida por Hahnemann (1989), como um mínimo de sintomas de valor máximo que caracteriza a maneira pessoal pela qual o doente faz sua doença, sinais e sintomas, estes que conduzem a escolha dos medicamentos que possibilitam a remoção da doença e a transformação em saúde.

Sob o domínio da DTM e DOF, cabe ao homeopata, agora clínico da dor, o estudo incessante das nuances e manifestações desta entidade patológica e a escolha da abordagem terapêutica homeopática que melhor convier ao paciente. Algumas destas possibilidades terapêuticas são descritas neste capítulos. 
A Homeopatia foi introduzida na humanidade por Christian Friedrich Samuel Hahnemann, nascido na cidade de Meissen, Alemanha no dia 10 de abril de 1755 . Terceiro filho de um casal de operários, dono de uma inteligência rara, que lhe conferiu, como autodidata, o domínio de vários idiomas, o gosto pela medicina e uma curiosidade peculiar aos pesquisadores. Em 1779, defendeu sua tese de doutoramento em medicina na Universidade de Erlangen, exercendo a profissão até $1787^{8}$.

A literatura registra seu sucesso profissional, com vasta clientela e relativa prosperidade, acompanhada de profunda desilusão e insatisfação com os meios curativos de sua época, comumente, agressivos e cheios de efeitos colaterais, por vezes levando o paciente ao óbito, Hahnemann abandona a prática médica e dedica-se a tradução de obras científicas. Foi traduzindo a Matéria Médica de Cullen, que iniciou os estudos e pesquisas que iria mais tarde consolidar sob a forma de princípios, regras e medicamentos, a terapêutica homeopática.

Hahnemann, em 1796, publicou seu primeiro trabalho sobre a nova doutrina: "Ensaio sobre as propriedades curativas das substâncias medicamentosas com algumas considerações sobre os métodos precedentes". Em 1805 e 1806 foram publicados os artigos "Esculápio na balança" e "medicina da experiência”.

Sua principal obra foi, em 1810, “Organon da arte de Curar”, publicação da qual preparou 6 (seis) edições e foi seguida pelas publicações da "Matéria Médica Pura" e o “Tratado das Doenças Crônicas”. Deixou, assim, um legado de conteúdo filosófico e científico que norteia a prática da homeopatia na humanidade até os dias de hoje.

No ano de 1835, casa-se pela segunda vez aos 80 anos, deixa a Alemanha e passa a residir em Paris, onde obteve autorização para exercer a medicina. Apesar de sua idade avançada, dedicou-se a esclarecer sua doutrina e formar novos discípulos. Faleceu aos 88 anos de idade em Paris, no dia 02 de julho de 1843.

\section{Princípios Gerais}

Como observador livre de precon- ceitos, o homeopata sabe que a presença de sinais e sintomas representa um estado de desordem. A doença significa somente uma mudança do estado de equilíbrio do indívíduo, Kent (1996). Para corrigir este estado, Hahnemann observou:

\subsection{Lei dos Semelhantes}

O fenômeno da cura depende inteiramente da lei primária da homeopatia, "Similia Similibus Curentur".

A Lei dos semelhantes aparece pela primeira vez, nos escritos de Hipócrates (460 - 370 a.C.), "o que dá febre a um homem são, cura um homem doente". Toda a postura filosófico-científica dos hipocráticos, a valorização do doente e não da doença, a observação clínica e individualização do ser humano, foram princípios influenciaram Platão que tomava a medicina como método fundamental para se adquirir conhecimento. Mais tarde Paracelso (1514 - 1564), químico competente, não se limitou em apreciar os efeitos dos medicamentos, buscava princípios ativos ocultos em cada substância para chegar a medicamentos puros, cuja propriedade de determinadas ervas e raízes, responsáveis pelo aparecimento de doenças, promoveriam em sua forma pura o tratamento para esta enfermidade. Já no fim do século XVII, Isac Newton, na análise da lei da gravitação universal, mostra a relação permanente dos semelhantes e lê-se em sua obra o princípio: "Similia similibus".

Hahnemann, sensibilizado pela observação dos pensadores que o precederam e com os registros na Matéria Médica do Dr. Willian Cullen da toxicologia de uma substância química conhecida como China ou extrato de quinino e sua semelhança com os sinais e sintomas da malária, iniciou sua utilização no tratamento de pacientes com esta doença. Estabelecendo a Lei dos semelhantes, "uma afecção dinâmica mais fraca é extinta de modo permanente no organismo vivo por outra mais forte, quando esta última seja semelhante à primeira em suas manifestações”.

\subsection{Experimentações no Homem São.}

Como pesquisador, a comprovação da primeira lei homeopática conduziu Hahnemann e seus discípulos à segunda 
máxima homeopática: "A experimentação no homem são". Algumas substâncias na natureza, sendo elas do reino vegetal, animal ou mineral, são capazes de produzir em indivíduos saudáveis sinais e sintomas característicos de intoxicação, estes foram à base das pesquisas que Hahnemann e seus discípulos, considerados sadios, registraram de cada substância escolhida como medicamento homeopático. Nas suas experiências em 40 anos consecutivos, foram estudados um total 61 medicamentos VASCONCELOS \& LACERDA (1990).

O trabalho consistiu em experimentar uma mesma substância em vários indivíduos saudáveis, catalogar os sinais e sintomas, característicos de cada medicamento, construindo, assim, a Matéria Médica Homeopática. O conjunto desses sintomas mentais, gerais e locais é chamado Patogenesia do medicamento.

O Repertório é o dicionário em que estão registrados os sinais e sintomas, em ordem alfabética e os medicamentos a estes relacionados durantes as experimentações. Portanto, os resultados encontrados por Hahnemann e seus discípulos são comprovados até hoje em cada prescrição homeopática, quando o homeopata submete os dados de sua anamnese à matéria médica e repertório homeopático, na busca de um medicamento em que a patogenesia seja a mais semelhante possível com as características mentais, gerais e físicas do paciente doente. TYLER (1965).

\section{3 Doses Infinitesimais}

Buscando eliminar a toxidade de algumas destas substâncias, Hahnemann preconizou sua diluição e também, por observação, constatou que estas substâncias diluídas, quando submetidas à agitação intensa tinham suas propriedades medicamentosas aumentadas. Uma forma de despertar a energia curativa do medicamento 9 .

Dinamizações é a associação sistemática de diluições a sucções, nome que recebeu o procedimento de agitação do frasco com o medicamento diluído contra um anteparo rígido. $\mathrm{O}$ número de dinamizações confere o que os homeopatas conhecem por potência do medicamento. Esta potência vai determinar o campo de ação do medicamento ${ }^{10} 16$.

Didaticamente, podemos considerar três níveis de cura em homeopatia:

$1^{\mathrm{o}}$ Nível de Cura preocupa-se com os sintomas locais o nível de similitude medicamento/patologia, não passa do sintoma físico e básico da manifestação patológica. Ex: Arnica Montana 6CH para contratura muscular de proteção. Considera-se a rigidez muscular, dor a palpação e limitação de movimentos 9,10 16.

$2^{\circ}$ Nível de Cura há a hierarquização dos sintomas, são valorizadas as manifestações mentais, sua ordem de aparecimento, características peculiares e gerais e, por último, sintomas locais.

Quanto maior a semelhança de sintomas do paciente com a patogenesia do medicamento, tanto melhor o prognóstico 9, 10 16. Ex: Arnica Montana 30CH para contratura muscular de proteção, após acidente de trânsito, com a presença de escoriações e hematomas no corpo, ausência de fraturas, indivíduo deprimido física e moralmente. Sensação de que o leito está duro e temor ao toque ou contato físico.

$3^{\text {o }}$ Nível de Cura, individualização do paciente, da patologia, valorização e hierarquização dos sintomas. Os sintomas mentais, a resposta psíquica do paciente ao acontecimento, no caso um acidente de trânsito. Suas alterações de humor, sono, choro, abandono, necessidade ou aversão a consolo.

Dificuldade de concentração, indiferença ou supervalorização aos sinais e sintomas apresentados, denunciam a necessidadedeumaabordagemindividualizada, da busca do medicamento simillimum, ou seja, o medicamento em que conjunto de sinais e sintomas registrados na Matéria Médica e Repertório Homeopático são os mais semelhantes possíveis com os do paciente ${ }^{9,10}$ 16. Após a escolha do medicamento, cabe ao homeopata determinar a melhor potência do medicamento e o intervalo de prescrição. VASCONCELOS \& LACERDA ${ }^{18}$ (1990).

\subsection{Medicamento Único}

Em conseqüência da metodologia instituída para o registro das características medicamentosas de cada substância, onde foi experimentada uma única droga por vez, Hahnemann recomendou no parágrafo $§ 273$ do Organon, que em hipótese alguma fosse

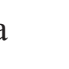

.

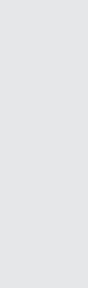


administrada mais de uma substância por vez, para cada doença e para cada momento do paciente, recomendam-se a repertorização dos sintomas, a escolha e administração de um só medicamento o mais semelhante possível com este $^{8,9,10,16}$.

Nesse princípio, os anos permitiram a formação de duas correntes terapêuticas dentro da filosofia homeopática. O Unicismo, em que o terapeuta busca o medicamento único para cada paciente e patologia 9,10,16 O Pluricismo, em que o terapeuta permitese fazer a indicação de mais de dois medicamentos por paciente-patologia, porém, com a ingestão alternada entre eles ${ }^{9,10,16}$. O complexismo, uma subdivisão do Pluricismo, em que numa mesma receita são elaborados complexos com mais de dois medicamentos em um único frasco, para o mesmo paciente e direcionados a sintomas diferentes. Ainda assim, o ideal de todo homeopata é encontrar o Simillimum do paciente, medicamento em que o grau de semelhança com o indivíduo promove a verdadeira cura do ser indivisível. HAHNEMANN $^{9}$ (1989).

\section{Teoria Miasmática}

Nas duas últimas décadas de sua vida, Hahnemann faz um estudo sobre as doenças em geral e concebe a Teoria Miasmática, uma proposta de causa e terapêutica que abrange a doença crônica e aguda. Diante da constatação de que a aplicação da lei dos semelhantes para casos agudos não era suficiente para a cura do que Hahnemann denominou miasmas crônicos, que é o conjunto de fatores predisponentes a estados patológicos, que acometem o indivíduo, referente a fatores hereditários, biotipologia ou constituição, temperamento, herdados ou adquiridos 6,18,2.

Foram descritos e estudados por Hahnemann três miasmas crônicos, aos quais atribuiu origem infecciosa, características hereditárias e poder dinâmico: A Psora, Sicose e Sífilis, mais tarde o Tuberculinismo foi introduzido por Nebel, homeopata suíço. EGITO $^{6}$ (1980).

Cada diátese possui um grupo de sinais, sintomas e enfermidades que lhe são peculiares. Ao profissional de saúde cabe somar detalhes, a observação minuciosa, ocasionalmente, oculta ou confusa, mas que nunca deixam de estar presentes, para o diagnóstico da diátese.

Na verdade, é comum que o indivíduo seja trimiasmático, com maior ou menor predominância de um miasma sobre o outro. CASALE $^{3}$ (1995); NARDY \& ZELANTE ${ }^{13}$ (2001).

A teoria miasmática surgiu antes do descobrimento da microbiologia, ainda assim, Hahnemann associou o aparecimento e as características das diáteses a uma alteração por auto ou heterointoxicação crônica a qual é exposta, o indivíduo, geração após geração, ocorrendo suscetibilidades patológicas e reações anormais ${ }^{18}$.

\subsection{Psora}

Segundo Hahnemann ${ }^{9}$ (1989), Psora é originada do contágio da vesícula da Sarna, que causa o desequilíbrio na força vital do indivíduo, Caracterizado por hipertonia.

Referiu-se, o autor, como sendo este o miasma mais contagioso ao ser humano pois surge a partir da supressão iatrogênica ou espontânea de erupções cutâneas pruriginosas 9.

Os autores atuais complementam considerando a auto-intoxicação por hábitos sedentários, dieta hiperprotéica de refeições ligeiras, sem a efetiva eliminação de metabólicos e radicais livres do organismo. Excitação mental, ilusão, depressão, neuroses fóbicas e dermatopatias DULCETTI ${ }^{5}$ (1992).

A psora não é uma doença específica, trata-se de um estado dinâmico das doenças nela envolvidas. Uma pessoa não se torna doente porque é psórico, porém desenvolve doenças, as quais, devido ao fato de que sua diátese, ou terreno é predisposto $6,18,3,2$.

CARILLO JR ${ }^{2}$ (1997) considera que a psora afeta predominantemente a pele e mucosas, caracteriza-se por estados patológicos recidivantes ou alternantes, geralmente decorrentes de supressão mórbida, associada à auto e hetero intoxicação crônica.

Como características emocionais, o indivíduo psórico está sempre adiantado em seus pensamentos, vive com a mente projetada no futuro. $\mathrm{O}$ estresse, choques morais, conflitos de personalidade e comportamento criam autointoxicação mental. Sua ansiedade desencadeia uma serie de eliminações patológicas: diarréias, sudorese, vômitos, 
palpitações e falta de ar 6,18,3,2.

Em odontologia, cáries dentárias pela ingestão exagerada de carbohidratos, má higiene oral, supurações gengivais, síndrome da ardência bucal e alterações inflamatórias agudas ${ }^{18,13}$, do ponto de vista constitucional, é mais comum em indivíduos de constituição carbônica e sulfúlrica. CARILLO JR² (1997); GARCIA $^{7}$ (1997).

\subsection{Sicose}

Hahnemann observou que várias manifestações dérmicas não correspondiam a psora, especialmente os condilomas granulomatosos que afetam órgãos genitais. Responsabilizou o contágio pela toxina blenorrágica a manifestação da Sicose.

Os sintomas da sicose são semelhantes aos da gonorréia, crescimento tissular patológico, alterações de forma e volume, secreções expessas persistentes, rinofaringites de repetição, reações anormais do sistema retículo - endotelial ${ }^{6,2}$. Alterações físicas diante de mudanças metereológicas e altos níveis de umidade, hidrogenismo, perverção moral e física. Este é o miasma da distonia ${ }^{18}$.

Os indivíduos mais reativos e predispostos são todos os biótipos, principalmente, o brevilíneo e o normolíneo gordo. Como características constitucionais carbônicos e sulfúricos gordos ${ }^{5,2}$.

O psiquismo dos sicóticos é bastante característico, marcado por idéias fixas, obsessivas, depressão, suicídio, ansiedade e indiferença. Sintomas que caracterizam a hipertrofia do ego fazem parte da si cose ${ }^{6,18}$.

Em odontologia, caracteriza por alterações oclusais do tipo Classe III representam bem alguns sinais constitucionais sic óticos. DULCETTI ${ }^{5}$ (1992) O aparecimento de verrugas, tumores benignos na cavidade bucal, sinusites, abscessos de progressão lenta, endurecidos ou fistulados com secreção purulenta abundante e espessa, nódulos pulpares, hiperplasia gengival ou pulpar. NARDY \& ZELANTE ${ }^{13}$ (2001).

\subsection{Sífilis}

Correspondeaindivíduospredispostos à sífilis ou que tenham antecedentes sifilíticos até a quinta geração ${ }^{18}$. Trata-se de uma diátese ulcerativa e com significante estágio de destruição.

EGITO $^{6}$ (1980) observou que quando o indivíduo é exposto a noxas, ou agressões de ordens variadas, superiores a sua capacidade de reequilíbrio, ou de intensidade noxal muito elevada, de ordem física ou mental, não havendo superação por meio de eliminações excretoras (Psora) ou secretoras (Sicose), há uma alteração em sua energia vital e sua células entram em processo autodestrutivo. A esse nível o organismo apresenta alterações funcionais acentuadas e perturbações histofisiopatológicas incompatíveis com a recuperação tecidual e mental do indivíduo ${ }^{6,18}$, 3,2 .

Caracterizado por hipotonia, diminuição do tônus da energia vital, condições de carências nutritivas, intercâmbios bioenergéticos alterados e incapacidade de absorção de nutrientes. Aparecimento de processos degenerativos e necróticos em diversos níveis celulares e teciduais ${ }^{13}$.

Os indivíduos predispostos são essencialmente biótipos mistos assimétricos. Todos os biótipos mistos: Sulfuro - fluóricos, fosfo - fluóricos e Carbo - fluóricos ${ }^{2}$.

Em seus estudos, CASALE ${ }^{3}$ (1995) observou a relação entre o miasma sifilínico, problemas do sistema ósseo e dentes, a ocorrência em ambos de amolecimento, supurações e formação de seqüelas e cáries. Osteomielites, degenerações, dentes desenvolvem-se pequenos, disformes, presença de hipoplasias, coloração escura e sem brilho. Assimetrias, anodontias. Arco dental irregular. Mobilidade, perda óssea periodontal e cáries prematuras. Tendência a protusão do maxilar e à formação de palato ogival. Discrepância osteodentárias com tipos Classe III e II e assimetria facial e hiperelasticidade ligamentar 5,7 .

Os portadores deste miasma apresentam ainda quadros recorrentes de cárie dentária e conseqüentes seqüelas, que afetam, sobretudo a vascularização dentária, com quadros de necrose pulpar, reabsorções apicais e outras patologias bucais ${ }^{7,18,13}$.

\subsection{Tuberculinismo}

Considerado uma associação miasmática dos três miasmas de Hahnemann, principalmente a Psora e a Sífilis. Qualquer 
sintoma do tuberculinismo é sempre resultante da manifestação de um dos três mecanismos EGITO $^{7}$ (1980).

Nebel, homeopata suíço, propôs o tuberculinismo como estado miasmático, porém o mestre Hahnemann já havia evidenciado o tubrculinismo como uma manifestação especial da psora ${ }^{7}$.

O tuberculinismo é uma impregnação hereditária ou adquirida da "toxina tuberculínica", resultante de distúrbios metabólicos primários e secundários. Porém, não é a doença tuberculose, trata-se de um estado caracterizado pela presença de uma "toxina", extremamente difundida e transmissível por hereditariedade e susceptível de permanecer latente, sem manifestar-se patologicamente. CARILLO JR² (1997).

É no aparelho respiratório que mais se evidência as manifestações tuberculínicas. Por condicionamento hereditário, o indivíduo adquire uma conformação anatômica especial do tórax: ombros encurvados, longilíneo, espaço subclavicular afundado e tórax comprimido. Expansão torácica limitada, tosse abundante, acúmulo de secreção favorece os processos infecciosos. O muco abundante é característico do tuberculinismo ${ }^{2,7}$.

Constituição desmineralizada, muito susceptível a mudanças térmica, hipotermia, sempre carrega consigo um agasalho. Alterações importantes no sistema linfoganglionar, adenite febril, emagrecimento progressivo $^{17,2,5,6,7}$.

Carência na absorção dos íons $\mathrm{Ca}, \mathrm{P}$, $\mathrm{Mg}, \mathrm{Cl}$ e $\mathrm{Na}$, manifesta-se como tendência ao emagrecimento, desidratação e descalcificação ${ }^{2}$.

Indivíduos predispostos são dos biótipos mistos, os fosfo-fluóricos são os mais sensíveis. Os brevilíneos (carbônicos) e assimétricos (fluóricos) apresentam-se mais resistentes, CARILLO Jr. ${ }^{2}$ (1997).

Em odontologia, são indivíduos predispostos a alterações estruturais óssea e dentárias. Grande propensão a desmineralização, reabsorção e degeneração. Hiperemia ganglionar, congestão venosa periférica (cianose) e tendência febril.

Psiquismo: indivíduos, desconfiados, irritabilidade, hipersensibilidade nervosa a fatos e comentários VASCONCELOS \& LACERDA $^{18}$ (1990).

EGITO ${ }^{7}$ (1980) conclui que, na prática, os quadros miasmáticos não são encontrados no estado puro, isolados. Por isso, os miasmas descritos por Hahnemann, servem para identificar cada miasma predominante em cada quadro patológico e estabelecer o tratamento adequado.

A progressão miasmática no organismo deve-se as seguintes condições:

- Intensidade da noxa (agressão);

- Especificidade da noxa;

- Bloqueios dos dispositivos de eliminação.

\section{Biotipologia Homeopática}

Outros seguidores de Hahnemann observaram que, durante a experimentação pura dos medicamentos em indivíduos sãos, alguns se mostravam mais susceptíveis a desenvolver sinais e sintomas frente à mesma substância.

No século XX, o médico homeopata Antoine Nebel propôs uma classificação biotipológica considerando o sistema músculoesquelético como responsável pela morfologia; considerou o funcionamento endócrino do eixo hipófise - tiróide e preocupou-se com a menor e maior suscetibilidade à tuberculose ${ }^{2,7}$.

Mais tarde, Leon Vannier desenvolveu os estudos de Nebel, relacionou a constituição fosfórica à tuberculose e a fluórica à sífilis. Justificando a nomenclatura pela semelhança com a experimentação de três medicamentos principais destas constituições: Calcarea carbonica, Calcarea phosphorica e Calcarea fluorica. VANNIER ${ }^{17}$ (1992)

$\mathrm{Na}$ década de 40, Henri Bernard daria impulso revolucionário à biotipologia. Classificou os indivíduos em três tipos básicos segundo o conceito bioquímico (carbônicos, sulfúricos e fosfóricos), subdividindo-os em tipos secundários (sulfúricos escleróticos, neutros e magros).

Ainda segundo CARILLO Jr. ${ }^{2}$ (1997), corrigiu o engano cometido por Nebel e deslocou o tipo carbônico da posição de equilíbrio, considerando-o como hipocrínico, admitindo, além disso, o fluórico como variação do fosfórico. Considerou o desenvolvimento constitucional sob a forma, função e o psiquismo acreditavam nas modificações lentas ou súbitas, fulgazes ou prolongadas, que acrescentavam caracteres variáveis ${ }^{2}$. 


\subsection{Constituição Sulfúrica}

Indivíduos de estatura mediana, normolíneos, peso e aspecto geralmente harmônicos entre as distintas partes do corpo. Durante o seu desenvolvimento tem tendência a apresentar fenômenos de autointoxicação progressiva com alterações metabólicas que determinam falhas nutritivas.

Psiquismo: pode apresentar-se como um sujeito equilibrado, moderado em suas ações, em seu estado de desequilíbrio apresenta-se muito irritado e nervoso. Facilmente impressionável antes de tratamentos odontológicos. Ao menor esforço, ficam fatigado, impaciente e reflexivo $7,2,18$.

Mesomorfia predominância de tecido muscular ${ }^{7}$.

Elasticidade normal, formando um ângulo de aproximadamente $170^{\circ}$, medida de diâmetros bicondilares de Humero, na extensão dos braços e Fêmur, VANNIER ${ }^{17}$ (1992).

Harmonia entre os membros, mãos equilibradas, simetria facial, tendência a dentes e face retangulares. Erupção normal dos dentes, cáries incipientes associadas ao consumo de carboidratos, cavidades pulpares amplas. Grande suscetibilidade a respostas inflamatórias agudas e tendência à supuração. Hiperemia pulpar. Estomatite aftosa ${ }^{7,2,13}$.

Arcadas dentárias circulares, apresentando o palato ligeiramente ogival. $\operatorname{GARCIA}^{7}(1999)$.

\subsection{Constituição Carbônica}

É um indivíduo brevilíneo, robusto, peso superior à média, predomínio de tecido adiposo. Apresenta alterações no metabolismo de cálcio ${ }^{2}$.

Indivíduos lentos apresentam patologias de evolução lenta e crônica, retenção hídrica, artrite, doenças degenerativas, hipertensão arterial CARILLO JR². (1997).

Psiquismo: Geralmente tímido, calmo, ordeiro e bem humorado. Passivo ao tratamento odontológico. Grande capacidade de autocontrole sobre o seu medo $0^{7,2,18}$. A criança geralmente somatiza suas angústias com o hábito de sucção de dedos. GARCIA ${ }^{7}$ (1999).

Hipoelasticidade formando um ângulo menor que $160^{\circ}$, na extensão dos braços, VANNIER ${ }^{17}$ (1992).

Endomorfia, predominância de tecido adiposo, presença de pregas cutâneas e encurtamento do Tríceps, subescapular e suprailíaco ${ }^{7}$.

Erupção lenta ou retardada, cáries de avanço lento de segundo grau. Hipercalcificação pulpar, dentinária e de condutos radiculares, pólipos pulpares. Hipercementose, tendência a anquilose, hipertrofia de amigdalas e adenóides ${ }^{7,2,13}$.

\subsection{Constituição Fosfórica}

Indivíduos de estrutura superior à média, longilíneos, baixo peso em relação à altura. Membros superiores e inferiores longilíneos, delgados, mãos finas, dedos são mais largos que a palma das mãos. Tendência a face descrita com o formato de um triangulo isóscele de vértice inferior?

Psiquismo: Ciclotímico, tendência à irritabilidade e a deprimir-se. Caráter variável, debilidade nervosa, sem resistência física e mental. Inteligente, esperto, porém esgota-se ao menor esforço intelectual ${ }^{7,2,18}$.

Ectomorfia ou predomínio de formas lineares, debilidade de peso e índice de altura pondera ${ }^{17}$.

A extensão das extremidades superiores completa, formando um eixo de $180^{\circ}$, VANNIER ${ }^{17}$ (1992).

Apresentam erupção de dentes retardadas, de coloração branco translúcido, ocasionalmente, zonas de desmineralização, dentinogenese imperfeita, caries por desmineralização, artrite nas ATMs, neuralgia facial, osteomielite da mandíbula, atraso nas cicatrizações ósseas e consolidação de fraturas, respiradores bucais e tendência a hiperplasia de adenóides. Incidência de palato ogival e arcadas em elipse com o eixo Antero - posterior maior. Grande propensão a reabsorções radiculares, idiopáticas, por movimentos ortodônticos 7,2 .

\subsection{Constituição Fluórica}

Indivíduos de estatura variável, normalmente, inferior à média, tecidos flácidos, musculatura e ligamentos elásticos que permitem posições e movimentos extremos. Caracteriza-se por apresentar assimetrias e distrofias osteo - conjuntivas.

A face, cabeça e corpo podem 
assemelhar-se ao formato de um triângulo escaleno ou um polígono irregular. Indivíduo marcado pela assimetria. Suas alterações corporais podem caracterizar verdadeiras alterações morfológicas de tamanho e número, como a microcefalia, polidactilia e outros ${ }^{7,2}$.

As características do fluórico podem modificar -se em outros três biótipos mistos: sulfofluóricos, carbofluóricos e fosforofluóricos ${ }^{2}$.

Psiquismo ciclotímico de caráter imprevisível, desatento, hiperatividade ou hipoatividade, imprudente, cinismo com tendências destrutivas. Paradoxal, pode apresentar-se caprichoso e genial ou superficial, crítico e com déficit de atenção ${ }^{7,2,18}$.

$\mathrm{Na}$ avaliação corporal, encontramse assimetrias, diferentes graus de hiperelasticidade ligamentar e coordenação muscular?.

Dismorfia caracterizada por assimetria, mal formações ${ }^{7}$. A extensão das extremidades superiores completa, formando um ângulo maior que $180^{\circ}$, VANNIER ${ }^{17}$ (1992).

A erupção dental exageradamente tardia ou adiantada, lesões cariosas múltiplas de segundo e terceiro grau, nas superfícies oclusal e interproximal, cáries do tipo rampante. Palato acentuadamente, ogival e arcadas assimétricas ou em forma de $\mathrm{V}^{7}$. Tendência a necrose pulpar, hipoplasia de esmalte, frouxidão ligamentar, mobilidade ligamentar assintomática, raízes incompletas com sistema de canais radiculares múltiplos, com condutos acessórios e alterações morfológicas. Subluxação da ATM, osteoporose, reabsorções e degenerações ${ }^{72,13}$.

\section{Emoções e Suas Manifestações em DTM e DOF}

A seqüência temporal em que os sintomas aparecem é bastante interessante e reveladora. $\mathrm{O}$ ponto exato no tempo em que o sintoma se manifesta pode nos dar informações importantes sobre a área problemática na qual ele se manifesta daquela maneira.

Não se devem considerar unicamente os fatos exteriores, mas, sobretudo os processos interiores. Os pensamentos, assuntos e divagações que ocupavam a mente quando o sintoma apareceu, o estado de ânimo, e a que nível reacional se encontrava o paciente.
DETHLEFSEN \& DAHLKE ${ }^{4}$ (1983).

No parágrafo $\S 208$, do Organon está registrado: " $A$ idade do paciente, seu modo de vida, sua dieta, profissão, relações sociais, da mesma forma sua disposição física e mental devem ser observadas a fim de saber se isto representa algum obstáculo ao tratamento”.

HAHNEMANN ${ }^{9}$, em 1989, observou que o processo de diluição pelo qual passavam os medicamentos homeopáticos para evitar os efeitos adversos vindos da toxidade de algumas substâncias, associados aos processos de sucções contínuas entre cada potência medicamentosa, proporcionavam resultados mais abrangentes aos tratamentos, resultados estes na esfera mental do paciente. Portanto, os sintomas mentais de cada medicamento estudado por Hahnemann e seus seguidores estão cuidadosamente registrados nas Matérias Médicas e Repertórios Homeopáticos. O que tem grande valor na escolha do medicamento e na hierarquização dos sintomas, normalmente, são os sintomas mentais, os mais consideráveis e marcantes da anamnese e da doença.

TEIXEIRA $^{15}$ (2002) propõe que, além dos sinais e sintomas clínicos referentes à enfermidade orgânica, as peculiaridades individuais relativas às esferas imaginária, emocional, volitiva, intelectiva, alimentar, exonerativa e inúmeras outras do âmbito generalista sejam valorizadas no entendimento da suscetibilidade ao adoecer.

Fatores como a indignação, frustrações, perdas, ruínas econômicas, traumas e ressentimentos repercutem diretamente na cavidade bucal e região orofacial. A raiva e o ódio expressos no aparelho estomatognático, principalmente, nas estruturas de sustentação, sob a forma de bruxismo, apertamento e traumas suscessivos ${ }^{18}$.

Os autores ainda sugerem que as emoções estão diretamente relacionadas à diátese do paciente, sendo fundamental o exercício da repertorização e a dinâmica miasmática para a escolha do medicamento, na patogenesia no qual estejam inseridos os sintomas desenvolvidos pelo paciente. A potência do medicamento diretamente relacionada ao nível de semelhança física e emocional entre medicamento / paciente ${ }^{10,5,18}$.

São considerados questionamentos importantes para a avaliação miasmática homeopática, principalmente nos aspectos emocionais: angústia, ansiedade, humor, 
impaciência, inquietude, insegurança, irritabilidade, medo e preocupações. Nos aspectos funcionais: apetite (apetência), funções fisiológicas, exonerações, sonhos, etc. TEIXEIRA ${ }^{15}$ (2002)

MESQUITA Jr. \& LAMBERT 12 (1990) realizaram uma análise no Repertório Homeopático de Kent-Eizayaga, comparando 64 grupos de sintomas afins existentes entre medo e ansiedade. Concluíram que 17 sintomas não apresentavam coincidência medicamentosa, o que representou $26 \%$ do total considerado. 47 sintomas apresentaram alguma coincidência de medicamentos, o que correspondeu a $73 \%$ do total considerado. Sete sintomas apresentaram coincidência completa entre medicamentos e sintomas. Concluem que o arsenal homeopático é rico em recursos medicamentosos, porém há necessidade de valorizar a totalidade sintomática para a eleição de um único medicamento bem indicado.

BEARZI et al. ${ }^{1}(1990)$, correlacionando os sintomas psicoafetivos e Asma em 42 crianças portadoras de asma e tratadas com homeopatia, observaram a melhora da asma em 40 crianças e a melhora dos distúrbios psicoafetivos em 37 crianças. Consideraram o tratamento homeopático eficaz, embora indicassem acompanhamento psicológico especializado as crianças que não apresentaram melhoras.

Diante da grandeza desta possibilidade terapêutica, a homeopatia e a diversidade de atuação dos medicamentos homeopáticos, Hahnemann preocupou-se em deixar aos seus seguidores a noção exata de que mais importante do que a doença é o doente. Este ser único e indivisível, a homeopatia não se encerra no diagnóstico e prescrição, mas na remoção de obstáculos que o perturbem, causem ou mantenham a doença. O que nos dias de hoje pode ser expresso em interdisciplinaridade.

\section{Obstáculos à Cura}

A odontologia não é exclusivamente técnica. È uma especialidade médica, lida com o ser humano, espiritual, mental, emocional e físico. Por vezes, para intervir nesta nobre forma de vida, é necessária a remoção dos obstáculos mecânicos à cura.
7, 186, 252, 260 e 261 reconhece que, na presença de obstáculos mecânicos, estes devem ser removidos por meios mecânicos para que, com o auxílio ou não da medicação homeopática, haja o restabelecimento do fluxo de energia vital que possibilita a condição de saúde. Cita como exemplos: a redução das luxações, a realização de suturas, abertura de caminhos de drenagem.

Desta forma, o clínico da dor reconhece e corrige fatores oclusais, alterações estruturais e funcionais possibilitando a cura. Numa atitude homeopática, buscando a totalidade dos sintomas, a semiologia detalhada, a atuação interdisciplinar e numa visão indivisível do ser humano, o clínico da dor encontra a cura e em alguns momentos, apenas o tratamento no alívio da dor.

\section{Referências}

1- BEARZI, G. et al Correlação entre síntomas psicoafetivos e asma, em crianças submetidas a tratamento homeopático. Revista de Homeopatia - APH. V.5 - no 2 - abr. mai. Jun. 1990

2- CARILlO Jr., R. Fundamentos de Homeopatia Constitucional. Morfologia, fisiologia e fisiopatologia aplicadas a clinica. $1^{a}$ edição São Paulo: Santos, 1997. 260 p.

3- CASAlE, J. A. Los Miasmas Crônicos Pertubacion Del Tono Bioenergético. $2^{\mathrm{a}}$ ed. Buenos Aires: Club de estudio, 1995. 189 p.

4- DETHLEFSEN, T \& DAHLKE, R. A doença como caminho. São Paulo: Cultrix, 1983. $262 \mathrm{p}$

5- DulCETTI Jr., O. Homeopatia em Odontologia. São Paulo: Andrei, 1992. 140p.

6- EGITO, J. L. Homeopatia - Contribuição ao Estudo da Teoria Miasmática. São Paulo: Elcid, 1980. 253 p

7- GARCIA G.G. Biotipologia Homeopática em Odontologia. Nueva Editorial Medico Homeopática Mexicana. 1ª Edição. México. 1999. $113 \mathrm{p}$. 
Homeopática. São Paulo: Giramundo, 1986. $1036 \mathrm{p}$

9- HAHNEMANN C. S. Organon da Arte de

Curar. São Paulo: Giramundo, 1989.176p

10- KENT, J. T. Filosofia Homeopática. $1^{\mathrm{a}}$

Edição traduzida português. São Paulo: Robe, $1996290 \mathrm{p}$

11- LATHOUD. Matéria Médica

Homeopática. Buenos Aires: Albatroz, 1998. $868 \mathrm{p}$.

12- MESQUITA Jr., A. \& LAMBERT, A.A.E. Ansiedade / medo: Estudo repertorial comparativo. Revista de Homeopatia - APH. V. 5 - nº - out.nov.dez. 1990

13- NARDY, R. O. \& ZELANTE, P.M. Miasmas na Cavidade Bucal. $1^{a}$ Edição CIC Computação - Itapira - 2001. 90 p

14- OKESON, J. P. Fundamentos de Oclusão e desordens temporomandibulares. São Paulo: Artes médicas, 2000. 500p

15- TEIXEIRA, M.Z. Avaliação miasmática na pesquisa clínica homeopática: Emprego de questionário de qualidade de vida, Revista de Homeopatia-APH. v. 67 no 1-2-3-4. 2002

16- TYLER M. L. Curso de Homeopatia. $1^{\mathrm{a}}$ Edição em português. Agencia Central. Rio de Janeiro. 1965. 287 p

17- VANNIER, L. Typology in Homoeopathy. Beaconsfield Publishers LTD - Bucks. England. 1ª published un England. 1992. 176 $\mathrm{p}$

18- VASCONCELOS J. V. \& LACERDA, P. Homeopatia Aplicada à Odontologia. Livraria e Editora Santos. $1^{\mathrm{a}}$ Edição. São Paulo

Informação bibliográficas:

Conforme a NBR 6023:2002 da Associação Brasileira de Normas Técnicas (ABNT), este texto científico publicado em periódico eletrônico deve ser citado da seguinte forma:

NARDY, Rosy de Oliveira. A Homeopatia Aplicada a Desordem Temporomandibular e Dor Orofacial. Cadernos UniFOA, Volta Redonda, ano III, n. 6, abril. 2008. Disponível em: <http://www.unifoa.edu. br/pesquisa/caderno/edicao/06/63.pdf> 